\title{
Comparative Assessment of Knowledge, Attitude/Practices and Prevention of Lassa Fever Among Community Dwellers and Contacts of Confirmed Patients in Endemic Areas of Ondo State, Nigeria
}

Olufemi Samuel Amoo, Joseph Ojonugwa Shaibu, Olumuyiwa Salu, Ifeoma Idigbe, Adesola Z. Musa, Gboyega Famokun, Oliver Ezechi, Babatunde Lawal Salako, Sunday Omilabu, and Rosemary Audu

\section{ABSTRACT}

The current resurgence and transmission dynamics of Lassa fever (LF) within an endemic community in Nigeria calls for concern. Lassa fever virus is known to be transmitted from rodents to humans as well as from human to human. This study aims to compare the knowledge, attitude/practices, and prevention of Community dwellers (CD) and Contacts of confirmed Lassa fever patients $(\mathrm{CCP})$ with respect to $L F$ in an endemic area in Nigeria.

This is a comparative cross-sectional study conducted between 2018 and 2019 during an outbreak of $\mathrm{LF}$ disease in Ondo State, Nigeria. A total of 250 consenting CD and 104 CCP were randomly selected to participate in this study. They were administered semi-structured questionnaires which were analysed using SPSSv23. Lassa fever disease causative agents, mode of transmission and prevention as well as actions on response to Lassa virus infections were assessed among respondents. Data were analysed and presented using descriptive statistics at $95 \%$ confidence interval and $(p<0.05)$ level of significance.

The gender distribution for CD was 116 males and 134 females while for $\mathrm{CCP}$, it was 43 males and 61 females. Furthermore, radio $(\mathrm{CD}=\mathbf{5 5 . 8 \%}$, $\mathrm{CCP}=20.8 \%)$ and public health campaign $(C D=40.4 \%, C C P=26.5 \%)$ were the major sources of information on Lassa fever among respondents. A larger fraction of $\mathrm{CCP}(\mathbf{1 2 . 5 \%})$ erroneously believe mosquitoes are the mode of transmission of Lassa fever compared to CD (4.2\%). Comparison also showed that higher proportion $(60.6 \%)$ of $\mathrm{CCP}$ exhibits poor attitude/practices to Lassa fever infection compared to $4 \%$ of CD. Level of education for both $\mathrm{CD}$ and $\mathrm{CCP}$ respondents were statistically significantly associated with knowledge and prevention of Lassa fever.

Comparatively, our study showed poor awareness on Lassa fever diseases, erroneous believes and need for positive attitudinal changes and practices towards LF prevention and control in affected communities.

Keywords: Community dwellers, contact of confirmed patient, endemic area, lassa fever.
Submitted : July 1, 2021

Published : August 19, 2021

ISSN: 2593-8339

DOI: $10.24018 /$ ejmed.202 1.3.4.962

Olufemi Samuel Amoo*

Center for Human Virology and Genomics, Microbiology Department, Nigerian Institute of Medical Research, Nigeria.

(e-mail: fhemy2003@yahoo.com)

Joseph Ojonugwa Shaibu

Center for Human Virology and

Genomics, Microbiology Department, Nigerian Institute of Medical Research, Nigeria.

Olumuyiwa Salu

Center for Human and Zoonotic Virology, Central Research Laboratory, College of Medicine, University of Lagos, Nigeria.

Ifeoma Idigbe

Clinical Sciences Department, Nigerian Institute of Medical Research, Nigeria. Adesola Z. Musa

Monitoring and Evaluation Unit, Nigerian Institute of Medical Research, Nigeria.

Gboyega Famokun

Disease Surveillance and Notification, Ondo State Ministry of Health, Nigeria. Oliver Ezechi

Clinical Sciences Department, Nigerian Institute of Medical Research, Nigeria. Babatunde Lawal Salako

Clinical Sciences Department, Nigerian Institute of Medical Research, Nigeria. Sunday Omilabu

Center for Human and Zoonotic Virology, Central Research Laboratory, College of Medicine, University of Lagos, Nigeria.

Rosemary Audu

Center for Human Virology and Genomics, Microbiology Department, Nigerian Institute of Medical Research, Nigeria.

*Corresponding author 


\section{INTRODUCTION}

Lassa fever is identified as an acute haemorrhagic infection caused by the Lassa virus, a bi-segmented ambisense single-stranded RNA virus that belongs to the family Arenaviridiae. It was first described in 1969 in the town of Lassa located in the North-Eastern part of Nigeria [1]. It is a highly communicable disease with an incubation period of 2-21 days [2], [3]. This haemorrhagic fever presents with signs and symptoms similar to those common with other viral and bacterial infections and hard to differentiate from those of febrile illnesses such as malaria, typhoid and other haemorrhagic fevers such as Ebola [2]. Some of the major symptoms of Lassa fever include fever, general weakness, headache, sore throat, muscle pain, cough, chest pain, nausea, vomiting, diarrhoea, abdominal pain with or without bleeding. It can also cause deafness which has a psychosocial impact on the victim as well as other multisystem complications, Ogbu and Uneke [4], [5]. Lassa fever is zoonotic and is transferred from rodents to humans, specifically through the multimammate rat, (Mastomys natalensis). These rats are typically found in households and human settlements, and cause infections via food contaminated with their faeces or urine [6], [7], [3] or when they are consumed as food [7]. The ubiquitous nature of these rats' stems from anthropological activities including unplanned urbanization, indiscriminate refuse disposal, poor personal hygiene, and overcrowded housing, which create conditions that attract the rodents [8]. The virus also has the capacity for person-to-person spread, either within households, during care for sick relatives or in health care settings [9].

The causes of death in Africa have been dominated by communicable diseases and many have died as a result of poor or lack of knowledge and ignorance of the Lassa fever disease [10], [11]. Lassa fever has been reported to be endemic to West-African countries particularly countries like Liberia, Nigeria, Guinea, and Sierra Leone [12]. The World Health Organization (WHO) statistics on Lassa virus infection in Nigeria have shown that every year, about 100,000 to 300,000 persons are infected and approximately 5,000 people die from the infection. This clearly is not in line with the One Health Campaign and the $10^{\text {th }}$ aspiration of the African Union Agenda (vision 2063), which seeks for quality life, sound health and wellbeing for all Nigerians by 2063 [13]. Studies have also revealed that, Lassa fever outbreaks in Nigeria are most common in rural areas and hospital settings, occasioned by socio-cultural practices, poor environmental and personal hygiene, and poor precautionary measures for the control of such disease [14].

According to [12], [15] reports, factors that enhance the outbreak of Lassa fever are still present in Nigeria. The year 2018 recorded the worst outbreak of Lassa fever throughout the world with a significant number of infections and deaths recorded [16] and there have been recurrent cases of suspected Lassa fever in Nasarawa, Edo, Ondo, Gombe, Taraba, Bauchi, Ebonyi, Anambra, Yobe, Rivers and Plateau States of Nigeria [17]. Therefore, the creation of awareness about Lassa fever cannot be overemphasized and should be investigated in every case of severe febrile illness in endemic regions of the country. This will only be possible when the general populace has adequate knowledge and information about the disease and are sensitized on care and safety. This will facilitate prevention, early detection of the disease and management of cases, particularly, contacts that have been exposed to the disease [2].

Ondo state in Nigeria is one of the endemic states with infection occurring all year round. Although studies have been carried out in the state, there is a need for a comparative assessment of the awareness and sensitization within the state. This will be useful in the development of health campaigns and health education messages in curtailing and possibly eliminating the danger that Lassa fever poses to the people. Therefore, this study aimed to assess and compare the knowledge, attitude/practices, and prevention of Lassa fever among community dwellers and contacts of confirmed patients in Lassa fever endemic areas of Ondo State.

\section{Methodology}

The study was a comparative cross-sectional study conducted in 2018 during an outbreak of Lassa fever disease in Ondo State, South-West, Nigeria, in four (4) Local Government Areas affected by the Lassa fever outbreak.

\section{A. Sample Size Determination and Study Area}

A sample size using the Cochran formula for crosssectional studies was determined, using the formula; $\mathrm{n}=\frac{Z^{2} p q}{d^{2}}$ for the minimum sample size. Where $n=$ minimum sample size; $(\mathrm{Z})=1.96 ; \mathrm{p}=0.21 ; \mathrm{q}=0.79$ and $\mathrm{d}=0.04$; where a Lassa fever prevalence of $18 \%$ and an attrition rate of $10 \%$ was assumed. The sample size $(n)=337(\approx 340)$ was derived.

\section{B. Study Population}

This study was conducted among community dwellers (CD) and contacts of confirmed patients (CCP) in Ondo state. A total number of 354 people, comprising 250 community members and 104 contacts from four local government areas (Akure North, Ondo, Ose and Owo) were randomly selected and interviewed using a structured questionnaire.

\section{Data Collection}

Between April 2018 and April 2019 structured questionnaires were administered to both $\mathrm{CD}$ and CCP in communities where an outbreak had occurred, to assess knowledge, attitude/practices, and prevention on Lassa fever.

\section{Data Management}

Respondent data were entered and analysed using Statistical Package for Social Sciences (SPSS) v23. Descriptive analysis was presented as charts and tables and chi-square analysis carried out to determine any significant association between variables and a P-value of $<0.05$ was considered as significant. Multiple knowledge questions were used to grade their knowledge with a score of " 1 " for correct response and " 0 " for incorrect response. The percentage distribution of the scores was determined and then used to classify the respondents' knowledge level based on percentiles.

The questionnaires captured information on sociodemographic variables and information on Lassa fever. Knowledge of Lassa fever was assessed using a 20-point 
scoring system on basic knowledge of Lassa virus, disease cause, modes of transmission and treatment of Lassa fever. A score of less than 9.9 was assessed as poor knowledge; 1014.9 was assessed as fair knowledge while a score of $>15$ was assessed as good knowledge (Box I).

\begin{tabular}{|c|c|c|}
\hline $\mathrm{S} / \mathrm{N}$ & Knowledge of Lassa fever & Score \\
\hline 1 & What is the cause of this disease? & 2 \\
\hline 2 & Lassa fever is spread to man through? & 2 \\
\hline 3 & $\begin{array}{l}\text { What are the modes of transmission of Lassa } \\
\text { fever ( } 0.5 \text { point for any correct answer) }\end{array}$ & 4 \\
\hline 4 & $\begin{array}{l}\text { What is the duration of Lassa fever symptoms to } \\
\text { manifest after infection? }\end{array}$ & 2 \\
\hline 5 & $\begin{array}{l}\text { Do all persons infected with Lassa virus show } \\
\text { symptoms? }\end{array}$ & 2 \\
\hline 6 & $\begin{array}{c}\text { What are the most common symptoms associated } \\
\text { with Lassa fever? ( } 0.5 \text { point for any correct } \\
\text { answer) }\end{array}$ & 4 \\
\hline 7 & Is treatment available for Lassa fever & 2 \\
\hline \multirow[t]{2}{*}{8} & What is the treatment for Lassa fever & 2 \\
\hline & Total: $(<9.9=$ Poor; $10-14.9=$ Fair; $>15=$ Good $)$ & 20 \\
\hline
\end{tabular}

The attitude/practices of Lassa fever were assessed using an 18-point scoring system. A score of less than 8.9 was assessed as poor attitude/practices; 9-13.5 was assessed as fair attitude/practices while a score of $>13.5$ was assessed as good attitude/practices (Box II).

\begin{tabular}{|c|c|c|}
\hline \multicolumn{3}{|c|}{ BOX II: ATTITUDE ASSESSMENT FOR LASSA FEVER } \\
\hline $\mathrm{S} / \mathrm{N}$ & Attitude/Practices of Lassa Fever & Score \\
\hline 1 & $\begin{array}{l}\text { Raw and cooked food should be kept in closed } \\
\text { containers }\end{array}$ & 2 \\
\hline 2 & $\begin{array}{c}\text { Canned drinks should be washed before } \\
\text { consumption }\end{array}$ & 2 \\
\hline 3 & Cassava and yam should be dried along the road & 2 \\
\hline 4 & Lassa fever kill if not reported on time? & 2 \\
\hline 5 & $\begin{array}{l}\text { A discharged Lassa fever patient should be } \\
\text { accepted back into the community }\end{array}$ & 2 \\
\hline 6 & $\begin{array}{c}\text { A dead Lassa fever patient should be buried } \\
\text { according to your tradition and custom? }\end{array}$ & 2 \\
\hline 7 & $\begin{array}{l}\text { Burial rite should not be done in a patient who dies } \\
\text { suddenly of fever until reported to the health } \\
\text { authority }\end{array}$ & 2 \\
\hline 8 & I catch and prepare rodents as bush meat & 2 \\
\hline 9 & I spread foodstuff on the roadside for drying & 2 \\
\hline & Total: $(<8.9=$ =oor; $9-13.5=$ Fair; $>13.5=$ Good $)$ & 18 \\
\hline \multicolumn{3}{|c|}{ BOX III: PREVENTION ASSESSMENT FOR LASSA FEVER } \\
\hline $\mathrm{S} / \mathrm{N}$ & Prevention of Lassa Fever & Score \\
\hline 1 & $\begin{array}{l}\text { How do you prevent Lassa fever within the } \\
\text { community? ( } 0.5 \text { point for any correct answer) }\end{array}$ & 3.5 \\
\hline 2 & $\begin{array}{c}\text { Does Lassa virus have a preference in infecting any } \\
\text { age group or sex? }\end{array}$ & 2 \\
\hline 3 & $\begin{array}{c}\text { Hand washing will help prevent Lassa fever } \\
\text { infection. }\end{array}$ & 2 \\
\hline 4 & $\begin{array}{c}\text { Prevention of rats in the household can prevent } \\
\text { Lassa fever infection. }\end{array}$ & 2 \\
\hline 5 & $\begin{array}{c}\text { Early reporting of suspected Lassa fever infection } \\
\text { will save life }\end{array}$ & 2 \\
\hline 6 & $\begin{array}{l}\text { Early reporting of suspected Lassa fever involves } \\
\text { the following ( } 1 \text { point for any correct answer) }\end{array}$ & 4 \\
\hline 7 & $\begin{array}{c}\text { What precautions should be taken during burial of } \\
\text { a deceased Lassa fever patient? ( } 0.5 \text { point for any } \\
\text { correct answer) }\end{array}$ & 3 \\
\hline & Total: $(<9.25=$ Poor; 9.25-13.9=Fair; $>13.9=$ Good $)$ & 18.5 \\
\hline
\end{tabular}

The prevention of Lassa fever among the study groups were assessed and graded using an 18.5-point scoring system. A score of less than 9.25 was assessed as poor prevention; 9.25-13.9 was assessed as fair prevention while a score of $>13.9$ was assessed as good prevention measures (Box III).

Results were presented in frequencies, proportions, and percentages. Statistical significance of association between variables were assessed using Chi-square test with significance level set at $\mathrm{p}<0.05$.

\section{E. Ethical Approval}

Informed consent was obtained before participants were enrolled. Participation was voluntary and there were no consequences for non-participation. All information obtained has been kept confidential. Ethical approval was obtained from NIMR Institutional Review Board.

\section{RESULTS \\ A. Socio-Demographic Characteristics of Participants (Table I)}

A total of 354 respondents (250 CD and $104 \mathrm{CCP}$ ) participated in the study. This comprises $159(44.9 \%)$ male and $195(55.1 \%)$ female respondents. Overall, 257 (72.6\%) of the respondents in this study had a tertiary level of education and $255(72.0 \%)$ were married. In addition, the majority of the respondents fall within the age group category of $41-50$ (34.0\%) for CD and 21-30 (25.0\%) years for CCP with a mean age of $39.1( \pm 10.9)$ and $35.3( \pm 16.3)$, respectively. The association between Community Dwellers and Contact of Confirmed Patients for age group, marital status and level of education were statistically significant as $\mathrm{p}<0.05$ (Table I).

TABLE I: COMPARISON OF SOCIO-DEMOGRAPHIC CHARACTERISTICS OF RESPONDENTS AMONG COMMUNITY DWELLERS (CD) AND CONTACTS OF CONFIRMED PATIENTS (CCP)

\begin{tabular}{|c|c|c|c|c|c|}
\hline \multicolumn{6}{|c|}{ CONFIRMED PATIENTS (CCP) } \\
\hline Variables & $\begin{array}{c}\text { CD } \\
(n=250) \\
\text { Frequency } \\
(\%)\end{array}$ & $\begin{array}{c}\mathrm{CCP} \\
(\mathrm{n}=104) \\
\text { Frequenc } \\
\mathrm{y}(\%)\end{array}$ & $\chi^{2}$ & $\mathrm{df}$ & P-value \\
\hline & & Gender & & & \\
\hline Male & $116(46.4)$ & $43(41.4)$ & 0.758 & 1 & 0.384 \\
\hline Female & $134(53.6)$ & $61(58.6)$ & & & \\
\hline \multicolumn{6}{|c|}{ Age groups (years) } \\
\hline$<21$ & $15(6.0)$ & $19(18.3)$ & 20.233 & 4 & $0.000^{*}$ \\
\hline $21-30$ & $64(25.6)$ & $26(25.0)$ & & & \\
\hline $31-40$ & $56(22.4)$ & $19(18.3)$ & & & \\
\hline $41-50$ & $85(34.0)$ & $20(19.2)$ & & & \\
\hline$>50$ & $30(12.0)$ & $20(19.2)$ & & & \\
\hline Mean Age & $\begin{array}{c}39.1 \\
( \pm 10.9)\end{array}$ & $\begin{array}{c}35.3 \\
( \pm 16.3)\end{array}$ & & & \\
\hline \multicolumn{6}{|c|}{ Marital Status } \\
\hline Single & $49(19.6)$ & $41(39.4)$ & 26.588 & 4 & $0.000^{*}$ \\
\hline Married & $197(78.8)$ & $58(55.8)$ & & & \\
\hline Widowed & $1(0.4)$ & $4(3.9)$ & & & \\
\hline Separated & $3(1.2)$ & $0(0.0)$ & & & \\
\hline Divorced & $0(0.0)$ & $1(0.9)$ & & & \\
\hline \multicolumn{6}{|c|}{ Level of Education } \\
\hline None & $0(0.0)$ & $0(0.0)$ & $\begin{array}{c}101.94 \\
1\end{array}$ & 3 & $0.000^{*}$ \\
\hline Quranic & $0(0.0)$ & $0(0.0)$ & & & \\
\hline Primary & $7(2.8)$ & $16(15.4)$ & & & \\
\hline Secondary & $23(9.2)$ & $50(48.1)$ & & & \\
\hline Tertiary & $220(88.0)$ & $37(35.6)$ & & & \\
\hline Others & $0(0.0)$ & $1(0.9)$ & & & \\
\hline
\end{tabular}

*statistically significant.

B. Sources of Information on the Awareness and Mode of Transmission of Lassa Fever on Ondo State (Fig. 1 and 2)

The distribution of the sources of Information on the awareness of Lassa fever among respondents showed radio 
and public health campaigns as the major sources of awareness of Lassa fever, among the community dwellers (CD) and contacts of confirmed patients (CCP) (Fig. 1).

The assessment of the knowledge of respondents on the mode of transmission of Lassa fever revealed that $75.6 \%$ of $\mathrm{CD}$ and $58.7 \%$ of CCP, believed Lassa fever was transmitted by spreading food uncovered on the ground or surfaces, $20.4 \%$ of CD and $58.8 \%$ of CCP showed that Lassa fever could be transmitted by consuming contaminated food, while $58.8 \%$ of CD and $49 \%$ of CCP responded that transmission

of the disease can occur by handling or coming in contact with infected persons. Other modes of transmission assessed were; "Handling corpses: CD 43.6\% and CCP 30.8\%, use of contaminated utensils: CD $36.8 \%$ and CCP $36.5 \%$, hunting rodents: CD $29.6 \%$ and CCP $39.4 \%$, and unprotected sex with carriers: CD 30\% and CCP 25\%", respectively (Fig. 2).

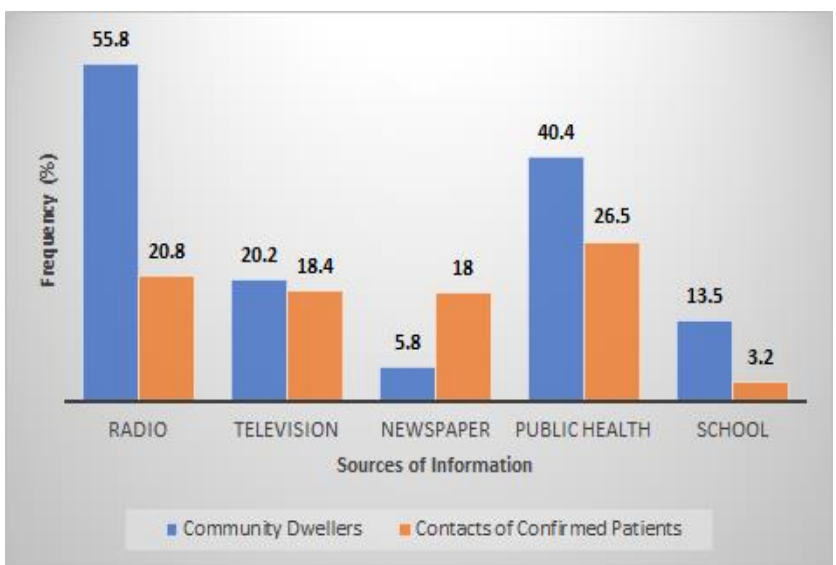

Fig. 1. Source of Information on the awareness of Lassa fever in Ondo State.

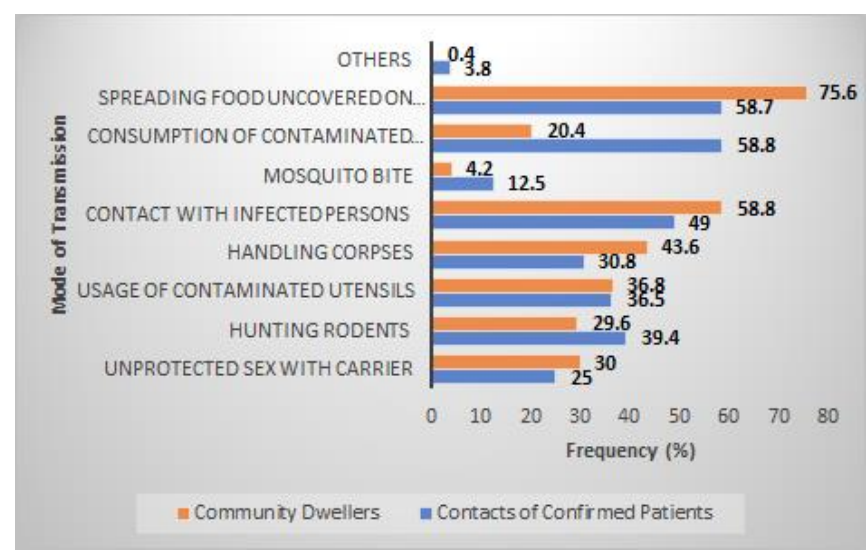

Fig. 2. Knowledge of Mode of Lassa fever Transmission.

\section{Behavioural Attitude and Cultural Beliefs on Lassa Fever Among Respondents}

Analysis showed that only $28.4 \%$ Community dwellers and $35.6 \%$ Contacts of Confirmed Patients agree that sexual contact with LF patients within three-weeks of illness can cause infection. Also, traditional burial practices for LF patients were a common practice among both the CD (26.1\%) and CCP (28.3\%). There exists some form of stigmatization among participants $(5.9 \% \mathrm{CD}$ and $5.4 \% \mathrm{CCP})$ while $11.6 \% \mathrm{CD}$ and $4.3 \% \mathrm{CCP}$ will prepare rodents as bush meat delicacies (Fig. 3).

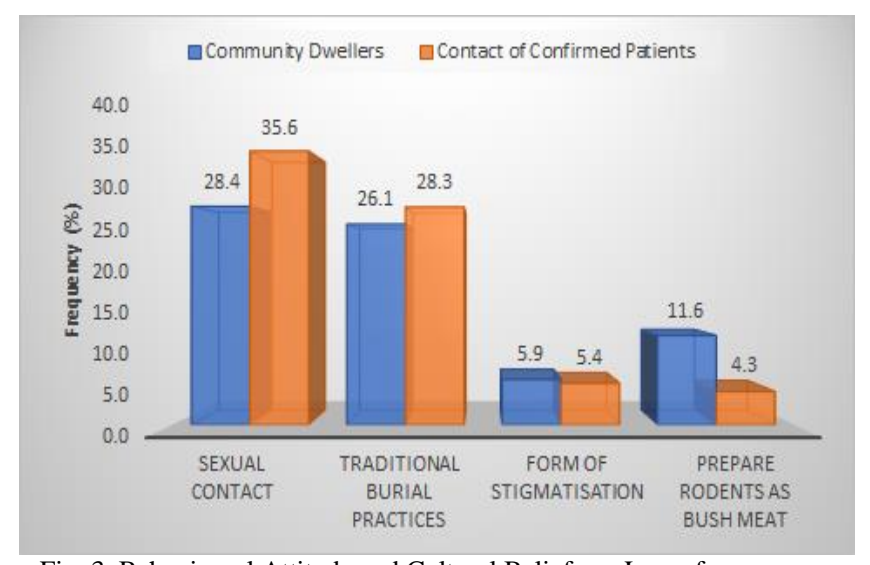

Fig. 3. Behavioural Attitude and Cultural Beliefs on Lassa fever among Respondents.

\section{Knowledge, Attitude/Practices and Prevention of Lassa Fever Among Respondents (Table II)}

Over $40 \%$ of male and female respondents had fair knowledge of Lassa fever. Generally, the differences in knowledge between respondents' level of education were found to be statistically significant $\left(\chi^{2}=20.464, p=0.002\right)$. There is no statistically significant difference in the respondents' knowledge based on marital status, age and sex groups.

Many respondents showed a good attitude towards Lassa fever with over 50\% within the age groups (21-30, 41-50, $50>$ years) and $60.3 \%$ within the age group 31-40 years. Also, male respondents had almost $63 \%$ of good attitudes compared to the female respondents $(48.7 \%)$ in the study. Over $67 \%$ of respondents who had a tertiary level of education had a good attitude towards the prevention of Lassa fever and about $61 \%$ who had a primary level of education had a poor attitude towards the prevention of Lassa fever. These findings were all found to be statistically significant among respondents except the age groups.

More than $50 \%$ of participants in all age groups in the study had a good level of Lassa fever prevention. Over $63.5 \%$ of the male respondents showed a good level of prevention compared to $53.8 \%$ of the female respondents. About $63.1 \%$ of married respondents were knowledgeable about the prevention of Lassa fever. Greater proportion (65.2\%) of participants with tertiary level of education had good Lassa fever infection prevention. The differences in prevention of Lassa fever awareness in the participants' levels of education and marital status were found to be statistically significant $\left(\chi^{2}=39.825, \mathrm{p}=0.000 ;\right.$ and $\chi^{2}=16.386, \mathrm{p}=0.037$, respectively).

\section{E. Association Between Study Groups' Knowledge,} Attitude/Practices and Prevention of Lassa Fever. (Table III)

Over $42 \%$ of both CD and CCP had fair knowledge about Lassa fever. Higher proportion $(60.6 \%)$ of CCP exhibits poor attitude/practices to Lassa fever infection compared to $4 \%$ of CD. However, $66.4 \%$ of CD had good Lassa fever prevention knowledge as compared to $38.5 \%$ of CCP. In all associations, the differences were statistically significant $\left(\chi^{2}=12.049\right.$, $\left.\mathrm{p}=0.002 ; \chi^{2}=209.002, \mathrm{p}=0.000 ; \chi^{2}=24.435, \mathrm{p}=0.000\right)$. 
TABLE II: AsSOCIATION BETWEen KNOWLEDGE, ATTITUde/PRACTICES AND PREVENTION MEASURES ON LASSA FEVER AMONG RESPONDENTS

\begin{tabular}{|c|c|c|c|c|c|c|c|c|c|c|c|c|}
\hline \multirow{2}{*}{ Variables } & \multicolumn{4}{|c|}{ Knowledge n=354; Frequency $(\%)$} & \multicolumn{4}{|c|}{ Attitude/Practices n=354; Frequency $(\%)$} & \multicolumn{4}{|c|}{ Prevention $\mathrm{n}=354 ;$ Frequency $(\%)$} \\
\hline & POOR & FAIR & GOOD & $\chi^{2}(\mathrm{P}$-value $)$ & POOR & FAIR & GOOD & $\chi^{2}$ (P-value) & POOR & FAIR & GOOD & $\chi^{2}(\mathrm{P}$-value $)$ \\
\hline \multicolumn{13}{|c|}{ Gender } \\
\hline Male & $32(20.1)$ & 73(45.9) & $54(34.0)$ & & 34(21.4) & $25(15.7)$ & $100(62.9)$ & 12.004 & $5(3.1)$ & $53(33.3)$ & 101(63.5) & \\
\hline Female & $39(20.0)$ & $83(42.6)$ & 73(37.4) & $0.518(0.772)$ & $39(20.0)$ & $61(31.3)$ & $95(48.7)$ & $\left(0.002^{*}\right)$ & $12(6.2)$ & $78(40.0)$ & $105(53.8)$ & $4.113(0.128)$ \\
\hline \multicolumn{13}{|c|}{ Age (years) } \\
\hline$<21$ & $6(13.3)$ & 20(44.4) & 19(42.2) & \multirow{5}{*}{$6.397(0.603)$} & $16(35.6)$ & $12(26.7)$ & $17(37.8)$ & \multirow{5}{*}{$\begin{array}{l}10.411 \\
(0.237)\end{array}$} & $2(4.4)$ & $18(40.0)$ & $25(55.6)$ & \multirow{5}{*}{$3.893(0.867)$} \\
\hline $21-30$ & $18(21.4)$ & $32(38.1)$ & $34(40.5)$ & & $16(19.0)$ & 23(27.4) & $45(53.6)$ & & $3(3.6)$ & $35(41.7)$ & $46(54.8)$ & \\
\hline $31-40$ & $18(24.7)$ & $31(42.5)$ & 24(32.9) & & $13(17.8)$ & $16(21.9)$ & $44(60.3)$ & & $5(6.8)$ & 29(39.7) & $39(53.4)$ & \\
\hline $41-50$ & $21(21.2)$ & 44(44.4) & $34(34.3)$ & & $16(16.2)$ & $24(24.2)$ & $59(59.6)$ & & $5(5.1)$ & $32(32.3)$ & $62(62.6)$ & \\
\hline$>50$ & $8(15.1)$ & $29(54.7)$ & $16(30.2)$ & & $12(22.6)$ & $11(20.8)$ & $30(56.6)$ & & $2(3.8)$ & $17(32.1)$ & $34(64.2)$ & \\
\hline \multicolumn{13}{|c|}{ Marital Status } \\
\hline Single & $17(18.9)$ & $45(50.0)$ & $28(31.1)$ & \multirow{5}{*}{$8.256(0.409)$} & $27(30.0)$ & $25(27.8)$ & $38(42.2)$ & \multirow{5}{*}{$\begin{array}{c}17.861 \\
\left(0.022^{*}\right)\end{array}$} & $3(3.3)$ & $47(52.2)$ & $40(44.4)$ & \multirow{5}{*}{$\begin{array}{c}16.386 \\
\left(0.037^{*}\right)\end{array}$} \\
\hline Married & $53(20.8)$ & $106(41.6)$ & 96(37.6) & & $44(17.3)$ & $58(22.7)$ & $153(60.0)$ & & $14(5.5)$ & $80(31.4)$ & $161(63.1)$ & \\
\hline Widowed & $0(0.0)$ & $3(60.0)$ & $2(40.0)$ & & $2(40.0)$ & $2(40.0)$ & $1(20.0)$ & & $0(0.0)$ & $1(20.0)$ & $4(80.0)$ & \\
\hline Separated & $0(0.0)$ & $2(66.7)$ & $1(33.3)$ & & $0(0.0)$ & $0(0.0)$ & $3(100.0)$ & & $0(0.0)$ & $2(66.7)$ & $1(33.3)$ & \\
\hline Divorced & $1(100.0)$ & $0(0.0)$ & $0(0.0)$ & & $0(0.0)$ & $1(100.0)$ & $0(0.0)$ & & $0(0.0)$ & $1(100.0)$ & $0(0.0)$ & \\
\hline \multicolumn{13}{|c|}{ Level of Education } \\
\hline None & $0(0.0)$ & $0(0.0)$ & $0(0.0)$ & \multirow{6}{*}{$\begin{array}{c}20.464 \\
\left(0.002^{*}\right)\end{array}$} & $0(0.0)$ & $0(0.0)$ & $0(0.0)$ & \multirow{6}{*}{$\begin{array}{c}70.734 \\
\left(0.000^{*}\right)\end{array}$} & $0(0.0)$ & $0(0.0)$ & $0(0.0)$ & \multirow{6}{*}{$\begin{array}{c}39.825 \\
\left(0.000^{*}\right)\end{array}$} \\
\hline Quranic & $0(0.0)$ & $0(0.0)$ & $0(0.0)$ & & $0(0.0)$ & $0(0.0)$ & $0(0.0)$ & & $0(0.0)$ & $0(0.0)$ & $0(0.0)$ & \\
\hline Primary & $3(16.7)$ & $12(66.7)$ & $3(16.7)$ & & $11(61.1)$ & $5(27.8)$ & $2(11.1)$ & & 2(11.1) & $11(61.1)$ & $5(27.8)$ & \\
\hline Secondary & $22(27.8)$ & $42(53.2)$ & $15(19.0)$ & & $29(36.7)$ & $30(38.0)$ & $20(25.3)$ & & $5(6.3)$ & $40(50.6)$ & $34(43.0)$ & \\
\hline Tertiary & $46(18.0)$ & 101(39.5) & $109(42.6)$ & & $32(12.5)$ & $51(19.9)$ & $173(67.6)$ & & $9(3.5)$ & $80(31.3)$ & $167(65.2)$ & \\
\hline Others & $0(0.0)$ & $1(100.0)$ & $0(0.0)$ & & $1(100.0)$ & $0(0.0)$ & $0(0.0)$ & & $1(100.0)$ & $0(0.0)$ & $0(0.0)$ & \\
\hline
\end{tabular}

*statistically significant.

TABLE III: KNOWLEDGE ATtitude/PRACTICES AND PREVENTION AMONG RESPONDENTS REGARDING LASSA FEVER

\begin{tabular}{|c|c|c|c|c|c|}
\hline Variables & POOR & FAIR & GOOD & $\chi^{2}$ & P-value \\
\hline \multicolumn{6}{|c|}{ Knowledge of Lassa fever } \\
\hline Community Dwellers (CD) & $42(16.8)$ & $105(42.0)$ & $103(41.2)$ & 12.049 & $0.002^{*}$ \\
\hline Contact of confirmed patients (CCP) & $29(27.9)$ & $51(49.0)$ & $24(23.1)$ & & \\
\hline \multicolumn{6}{|c|}{ Attitude/Practices of Lassa fever } \\
\hline Community Dwellers (CD) & $10(4.0)$ & $45(18.0)$ & 195(78.0) & 209.002 & $0.000^{*}$ \\
\hline Contact of confirmed patients (CCP) & $63(60.6)$ & 41(39.4) & $0(0.0)$ & & \\
\hline \multicolumn{6}{|c|}{ Prevention of Lassa fever } \\
\hline Community Dwellers (CD) & $8(3.2)$ & $76(30.4)$ & $166(66.4)$ & 24.435 & $0.000^{*}$ \\
\hline Contact of confirmed patients (CCP) & $9(8.7)$ & $55(52.9)$ & $40(38.5)$ & & \\
\hline
\end{tabular}

*statistically significant.

Contact of confirmed patients (CCP) 
European Journal of Medical and Health Sciences www.ejmed.org

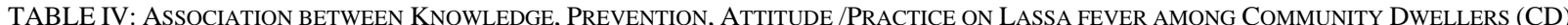

\begin{tabular}{|c|c|c|c|c|c|c|c|c|c|c|c|c|}
\hline \multirow{2}{*}{ Variables } & \multicolumn{4}{|c|}{ Knowledge $\mathrm{n}=250 ;$ Frequency $(\%)$} & \multicolumn{4}{|c|}{ Attitude/Practices n=250; Frequency (\%) } & \multicolumn{4}{|c|}{ Prevention n=250; Frequency $(\%)$} \\
\hline & POOR & FAIR & GOOD & $\chi^{2}$ (P-value) & POOR & FAIR & GOOD & $\chi^{2}$ (P-value) & POOR & FAIR & GOOD & $\chi^{2}$ (P-value) \\
\hline & & & & \multirow{4}{*}{$0.749(0.688)$} & & Gender & & \multirow{4}{*}{$\begin{array}{c}10.643 \\
\left(0.005^{*}\right)\end{array}$} & & & & \multirow{4}{*}{$3.300(0.192)$} \\
\hline Male & $18(15.5)$ & $52(44.8)$ & $46(39.7)$ & & $5(4.3)$ & $11(9.5)$ & $100(86.2)$ & & $2(1.7)$ & $31(26.7)$ & $83(71.6)$ & \\
\hline Female & $24(17.9)$ & $53(39.6)$ & $57(42.5)$ & & $5(3.7)$ & $34(25.4)$ & $95(70.9)$ & & $6(4.5)$ & $45(33.6)$ & $83(61.9)$ & \\
\hline & & & & & & Age (years) & & & & & & \\
\hline$<21$ & $2(1.1)$ & $12(54.5)$ & $8(36.4)$ & \multirow{5}{*}{$9.030(0.340)$} & $1(4.5)$ & $4(18.2)$ & $17(77.3)$ & \multirow{5}{*}{$4.094(0.849)$} & $0(0.0)$ & $5(22.7)$ & $17(77.3)$ & \multirow{5}{*}{$4.231(0.836)$} \\
\hline $21-30$ & $12(20.3)$ & 20(33.9) & $27(45.8)$ & & $4(6.8)$ & $10(16.9)$ & $45(76.3)$ & & $3(5.1)$ & $19(32.2)$ & $37(62.7)$ & \\
\hline $31-40$ & $11(20.8)$ & 19(35.8) & $23(43.4)$ & & $0(0.0)$ & $9(17.0)$ & $44(83.0)$ & & $2(3.8)$ & $19(35.8)$ & $32(60.4)$ & \\
\hline $41-50$ & $14(18.0)$ & $32(41.0)$ & $32(41.0)$ & & $4(5.1)$ & $15(19.2)$ & $59(75.6)$ & & $2(2.6)$ & $24(30.8)$ & $52(66.7)$ & \\
\hline$>50$ & $3(7.9)$ & 22(57.9) & $13(34.2)$ & & $1(2.6)$ & 7(18.4) & $30(78.9)$ & & $1(2.6)$ & $9(23.7)$ & 28(73.7) & \\
\hline & & & & \multirow{7}{*}{$8.047(0.235)$} & & Marital Status & & & & & & \\
\hline Single & $8(16.0)$ & $28(56.0)$ & $14(28.0)$ & & $2(4.0)$ & 10(20.0) & $38(76.0)$ & \multirow{6}{*}{$1.271(0.973)$} & $1(2.0)$ & $21(42.0)$ & $28(56.0)$ & \multirow{5}{*}{$6.722(0.347)$} \\
\hline Married & $34(17.3)$ & $75(38.3)$ & $87(44.4)$ & & $8(4.1)$ & $35(17.9)$ & $153(78.1)$ & & $7(3.6)$ & $53(20.7)$ & $136(69.4)$ & \\
\hline Widowed & $0(0.0)$ & $0(0.0)$ & $1(100.0)$ & & $0(0.0)$ & $0(0.0)$ & 1(100.0) & & $0(0.0)$ & $0(0.0)$ & $1(100.0)$ & \\
\hline Separated & $0(0.0)$ & $2(66.7)$ & $1(33.3)$ & & $0(0.0)$ & $0(0.0)$ & $3(100.0)$ & & $0(0.0)$ & $2(66.7)$ & $1(33.3)$ & \\
\hline Divorced & $0(0.0)$ & $0(0.0)$ & $0(0.0)$ & & $0(0.0)$ & $0(0.0)$ & $0(0.0)$ & & $0(0.0)$ & $0(0.0)$ & $0(0.0)$ & \\
\hline & & & & & & Education & & & & & & \\
\hline None & $0(0.0)$ & $0(0.0)$ & $0(0.0)$ & \multirow{6}{*}{$11.318\left(0.023^{*}\right)$} & $0(0.0)$ & $0(0.0)$ & $0(0.0)$ & \multirow{6}{*}{$0.911(0.923)$} & $0(0.0)$ & $0(0.0)$ & $0(0.0)$ & \multirow{6}{*}{$2.726(0.605)$} \\
\hline Quranic & $0(0.0)$ & $0(0.0)$ & $0(0.0)$ & & $0(0.0)$ & $0(0.0)$ & $0(0.0)$ & & $0(0.0)$ & $0(0.0)$ & $0(0.0)$ & \\
\hline Primary & $0(0.0)$ & $2(100.0)$ & $0(0.0)$ & & $0(0.0)$ & $0(0.0)$ & $2(100.0)$ & & $0(0.0)$ & $1(50.0)$ & $1(50.0)$ & \\
\hline Secondary & $4(14.8)$ & $18(66.7)$ & $5(18.5)$ & & 1(3.7) & $6(22.2)$ & $20(74.1)$ & & $0(0.0)$ & $11(40.7)$ & $16(59.3)$ & \\
\hline Tertiary & $38(17.2)$ & $85(38.5)$ & $98(44.3)$ & & $9(4.1)$ & $39(17.6)$ & $173(78.3)$ & & $8(3.6)$ & $64(29.0)$ & $149(67.4)$ & \\
\hline Others & $0(0.0)$ & $0(0.0)$ & $0(0.0)$ & & $0(0.0)$ & $0(0.0)$ & $0(0.0)$ & & $0(0.0)$ & $0(0.0)$ & $0(0.0)$ & \\
\hline
\end{tabular}

*Statistically significant.

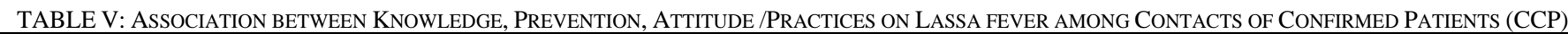

\begin{tabular}{|c|c|c|c|c|c|c|c|c|c|c|c|c|}
\hline \multirow{2}{*}{ Variables } & \multicolumn{4}{|c|}{ Knowledge $n=104 ;$ Frequency $(\%)$} & \multicolumn{4}{|c|}{ Attitude/Practices n=104; Frequency $(\%)$} & \multicolumn{4}{|c|}{ Prevention $n=104 ;$ Frequency $(\%)$} \\
\hline & POOR & FAIR & GOOD & $\chi^{2}(\mathrm{P}$-value $)$ & POOR & FAIR & GOOD & $\chi^{2}$ (P-value) & POOR & FAIR & GOOD & $\chi^{2}$ (P-value) \\
\hline & & & & \multirow{3}{*}{$1.210(0.546)$} & & Gender & & \multirow{3}{*}{$1.447(0.229)$} & & & & \multirow{3}{*}{$0.500(0.779)$} \\
\hline Male & 14(32.6) & $21(48.8)$ & $8(18.6)$ & & $29(67.4)$ & 14(32.6) & $0(0.0)$ & & $3(7.0)$ & $22(51.2)$ & $18(41.9)$ & \\
\hline Female & $15(24.6)$ & $30(49.2)$ & $16(26.2)$ & & $34(55.7)$ & $\begin{array}{l}27(44.3) \\
\text { Age (vears) }\end{array}$ & $0(0.0)$ & & $6(9.8)$ & $33(54.1)$ & $22(36.1)$ & \\
\hline$<21$ & $4(17.4)$ & $8(34.8)$ & $11(47.8)$ & \multirow{5}{*}{$14.470(0.07)$} & $15(65.2)$ & $8(34.8)$ & $0(0.0)$ & \multirow{5}{*}{$3.153(0.533)$} & $2(8.7)$ & $13(56.5)$ & $8(34.8)$ & \multirow{5}{*}{$6.124(0.633)$} \\
\hline $21-30$ & $6(24.0)$ & $12(48.0)$ & $7(28.0)$ & & $12(48.0)$ & $13(52.0)$ & $0(0.0)$ & & $0(0.0)$ & $16(64.0)$ & $9(36.0)$ & \\
\hline $31-40$ & $7(35.0)$ & $12(60.0)$ & $1(5.0)$ & & $13(65.0)$ & $7(35.0)$ & $0(0.0)$ & & $3(15.0)$ & $10(50.0)$ & $7(35.0)$ & \\
\hline $41-50$ & $7(33.3)$ & $12(57.1)$ & $2(9.5)$ & & $12(57.1)$ & $9(42.9)$ & $0(0.0)$ & & $3(14.3)$ & $8(38.1)$ & $10(47.6)$ & \\
\hline$>50$ & $5(33.3)$ & $7(46.7)$ & $3(20.0)$ & & 11(73.3) & $4(26.7)$ & $0(0.0)$ & & $1(6.7)$ & $8(53.3)$ & $6(40.0)$ & \\
\hline \multicolumn{13}{|l|}{ Marital Status } \\
\hline Single & $9(22.5)$ & $17(42.5)$ & $14(35.0)$ & \multirow{6}{*}{$9.593(0.143)$} & $25(62.5)$ & $15(37.5)$ & $0(0.0)$ & \multirow{6}{*}{$1.791(0.617)$} & $2(5.0)$ & $26(65.0)$ & $12(30.0)$ & \multirow{5}{*}{$7.189(0.304)$} \\
\hline Married & $19(32.2)$ & $31(52.5)$ & $9(15.3)$ & & $36(61.0)$ & $23(39.0)$ & $0(0.0)$ & & $7(11.9)$ & $27(45.8)$ & $25(42.4)$ & \\
\hline Widowed & $0(0.0)$ & $3(75.0)$ & $1(25.0)$ & & $2(50.0)$ & $2(50.0)$ & $0(0.0)$ & & $0(0.0)$ & $1(25.0)$ & $3(75.0)$ & \\
\hline Separated & $0(0.0)$ & $0(0.0)$ & $0(0.0)$ & & $0(0.0)$ & $0(0.0)$ & $0(0.0)$ & & $0(0.0)$ & $0(0.0)$ & $0(0.0)$ & \\
\hline Divorced & $1(100.0)$ & $0 .(0.0)$ & $0(0.0)$ & & $0(0.0)$ & $1(100.0)$ & $0(0.0)$ & & $0(0.0)$ & $1(100.0)$ & $0(0.0)$ & \\
\hline \multicolumn{11}{|l|}{ Education } & & \\
\hline None & $0(0.0)$ & $0(0.0)$ & $0(0.0)$ & \multirow{6}{*}{$4.959(0.549)$} & $0(0.0)$ & $0(0.0)$ & $0(0.0)$ & \multirow{6}{*}{$2.472(0.48)$} & $0(0.0)$ & $0(0.0)$ & $0(0.0)$ & \multirow{6}{*}{$\begin{array}{c}15.429 \\
\left(0.017^{*}\right)\end{array}$} \\
\hline Quranic & $0(0.0)$ & $0(0.0)$ & $0(0.0)$ & & $0(0.0)$ & $0(0.0)$ & $0(0.0)$ & & $0(0.0)$ & $0(0.0)$ & $0(0.0)$ & \\
\hline Primary & $3(18.8)$ & $10(62.5)$ & $3(18.8)$ & & $11(68.8)$ & $5(31.3)$ & $0(0.0)$ & & $2(12.5)$ & $10(62.5)$ & $4(25.0)$ & \\
\hline Secondary & $18(36.4)$ & $24(46.2)$ & $10(19.2)$ & & $28(53.8)$ & $24(46.2)$ & $0(0.0)$ & & $5(9.6)$ & $29(55.8)$ & $18(34.6)$ & \\
\hline Tertiary & $8(22.9)$ & $16(45.7)$ & $11(31.4)$ & & $23(55.7)$ & $12(34.3)$ & $0(0.0)$ & & $1(2.9)$ & $16(45.7)$ & $18(55.4)$ & \\
\hline Others & $0(0.0)$ & $1(100.0)$ & $0(0.0)$ & & $1(100.0)$ & $0(0.0)$ & $0(0.0)$ & & $1(100.0)$ & $0(0.0)$ & $0(0.0)$ & \\
\hline
\end{tabular}

*Statistically significant. 


\section{F. Association Between Knowledge, Attitude/Practices and Prevention on Lassa Fever Among Study Groups}

Among community dwellers, the association between level of education and Lassa fever knowledge as well as gender and attitude/practices to Lassa fever were statistically significant (Table IV) while Table V shows statistical significance (Pvalue $<0.017$ ) between respondents' level of education and knowledge of prevention of Lassa fever among CCP. However, there is no statistical association between gender, level of education and age groups among study groups in relation to Lassa fever knowledge and attitude/practices (Pvalue $>0.05)$.

\section{DISCUSSION}

Lassa fever is highly contagious and most likely will result in the death of infected persons if it is not detected or managed in time. This study identified use of radio (as the major media) and health campaign as the main sources of information on Lassa fever in communities in Ondo State. Though our study population is a mix of urban, semi-urban and rural areas, the reason for many opting for audio media might be as a result of technological advancement whereby radio stations now transmit on mobile phones. Also, the role of health campaigns identified in this study showed increased effort by the health sector to combat this deadly disease. This increased effort on the part of the health workers is in concordance with studies from other states (like Edo), with similar experiences of Lassa Fever outbreaks [18]-[20], [3]. Though this study was conducted in a community with most respondents attaining higher (tertiary) level of education, schools were the least source of information for respondents on knowledge of Lassa fever. This did not agree with the findings conducted in tertiary health institutions by Ekuma and Akpan [21] where the most common source of information was from School activity (lectures). This is understandable since our study settings differ from that of Ekuma and Akpan [21]. However, Adesoji et al [18] findings from a community in Ilorin Kwara State, also reported a lower percentage of respondents receiving information on Lassa fever from school. Hence, given the widespread endemicity of Lassa fever infection in Nigeria, there is a need for the introduction of Lassa fever education in academic curriculum (extra curriculum) across all states within the country. Although most of the respondents have tertiary education, this study showed that a reasonable number still have the erroneous belief that Lassa fever is transmitted by mosquitoes. This could account for the reason why hunting of rodents such as bush rats still persists despite the annual recurrent outbreak in the study area. Furthermore, our report agrees with previous studies that reported misconceptions in transmission of Lassa fever among respondents in a community study [18], [22].

It would be expected of community dwellers in states like Ondo with increased incidences of Lassa fever outbreaks in recent times to have a good knowledge of the disease. However, over $40 \%$ of the study population have a fair level of Lassa fever knowledge. This could be the reason why the Lassa fever outbreak is becoming perennial in States like Ondo. This, therefore, necessitates a form of emergency deployment of awareness tools in areas of the state where the outbreak of the disease persists which will be used in sensitization and health education on Lassa fever in the endemic communities of the state.

Furthermore, it is of great concern to have about $63 \%$ of the respondents in CCP study group demonstrating poor attitude/practices to Lassa fever. On the contrary, this was less evident among CD. This poor attitude could be responsible for the recent increased number of cases reported in Ondo State. Lack of knowledge that sexual intercourse within three weeks of infection and practices such as traditional burial rites on dead Lassa fever patients could also be a contributing factor to Lassa virus infection and spread.

Ogboghodo [23] reported a very high percentage of study subjects with poor Lassa fever preventive practices among $\mathrm{CD}$ in Edo State (known for persistence Lassa fever outbreaks in Nigeria). In contrast, our study revealed that CD had good preventive measures $(66.4 \%)$ and CCP had fair prevention measures $(52.9 \%)$. Furthermore, Olowookere [24] in a study among community dwellers in Ile-Ife, Osun State, also reported over fifty percent of respondents with poor attitude and practices of Lassa fever. Intensive public education on hygiene is necessitated among these communities to mitigate the deleterious consequences because of poor attitude to prevention and practices of prevention of Lassa fever. Though, the issue of stigmatization among respondents was minimal among the study groups (5.9\% CD and 5.4\% CCP), more effort is needed to demystify the myth surrounding the disease.

\section{CONCLUSION}

In conclusion, though there was a level of awareness among respondents, there is need by relevant stakeholders to intensify effort in educating members of the community on positive behavioural and attitudinal change in relation to factors influencing spread of Lassa fever and host of Lassa virus in the community. Furthermore, the poor level of awareness among contacts of confirmed patients when compared to community dwellers called for concern. Therefore, policy makers in endemic areas can leverage on the advance in technology through the use of e-health platforms, public health campaigns and radio transmissions freely available on many low-cost brands of mobile phone in the country to educate community dwellers on Lassa fever health awareness.

\section{CONSENT FOR PUBLICATION}

All participants consented before enrolment in the study. However, no individual person's data included in this publication.

\section{AVAILABILITY OF DATA AND MATERIALS}

The datasets used and/or analysed during the current study are available from the corresponding author on reasonable request. 


\section{COMPETING INTERESTS}

We declare no competing interest on this study.

\section{FUNDING}

The funding for this study was made available by the Nigerian Institute of Medical Research.

\section{AUTHORS' CONTRIBUTIONS}

OSA coordinated the research proposal, research activities, participated in the field work and write up of the draft manuscript. JS was involved in research activities and participated in the field work. OS, participated in the field work. II participated in the field work. ZM, questionnaire development. BF facilitated the field staff. OE participated in fieldwork, conducted and supervised project. BLS supervised the project. SO, facilitated field work activities and project supervision. RA, conceived the idea, supervised, and coordinated the developed research proposal, research activities, and proofread and corrected the draft manuscript. All Authors read and approved the final draft of the manuscript.

\section{ACKNOWLEDGMENTS}

This study was made possible by the support and leadership of the Nigerian Institute of Medical Research (NIMR), the Commissioner for Health, Ondo State and other Disease Surveillance and Notification Officers who supported the NIMR team in their various LGAs.

\section{REFERENCES}

[1] J. D. Frame, J. M. Baldwin Jr, D. J. Gocke, J. M. Troup, "Lassa fever, a new virus disease of man from West Africa. I. Clinical description and pathological findings," Am J Trop Med Hyg., 1970; 19:670-676.

[2] O. S. Ilesanmi, B. Omotoso, F. O. Alele, and P. Adewuyi, "Awareness of Lassa fever in a Rural Community in Southwest Nigeria". Journal of Community Health Research, 2015, 4(1):1-10.

[3] C. M. Odionye, L. I. Anorue, and O. Ekwe, "A Knowledge, Attititude and Practice (KAP) Analysis of Lassa fever Media Campaign among Residents of South-East, Nigeria" African Population Studies, 2019, 33(1): 4738-4749.

[4] O. Ogbu, E. Ajuluchukwu, and C. J. Uneke, "Lassa fever in West African sub-region: an overview" Journal of Vector Borne Diseases. 2007, 44(1):1-11.

[5] G. M. Adewuyi, A. Fowotade, and B. T. Adewuyi, "Lassa fever: Another Infectious Menace" African Journal of Clinical and Experimental Microbiology, 2009, 10(3): 144-155.

[6] T. Healing, and R. Gopal, "Report on an assessment visit to Sierra Leone," London: Merlin. April 12th-30th 2001.

[7] J. K. Richmond, and D. J. Baglole, "Lassa fever: epidemiology, clinical features, and social consequences." British Medical Journal, 2003, 327 (7426): 1271-1275.
[8] A. W. Olalekan. "Community awareness and perception towards rodent control: implication for prevention and control of Lassa fever in urban slums of south-western Nigeria," Malta Journal of Health Sciences, 2015; 2: 26-32.

[9] E. Tobin, "Assessment of Knowledge and Attitude Towards Lassa Fever Among Primary Care Providers in an Endemic Sub-Urban Community in Edo State: Implications for Control." Journal of Medicine and Medical Sciences. 2013, 4(8): 311-318.

[10] A. K. Adefisan, "The Level of Awareness that Rat is a Vector of Lassa Fever among the Rural People in Ijebu-North Local Government, Ogun State, Nigeria" Journal of Education and Practice, 2014, 5(37): 166171.

[11] J. O. Wogu, "Mass media awareness campaign and the prevention of the spread of Lassa fever in the rural communities of Ebonyi State, Nigeria: Impact evaluation." Journal of Public Health in Africa, 2018, 9(3): $179-184$.

[12] World Health Organisation. (2017). "Weekly Bulletin on Outbreaks and Other Emergencies", 1-15.

[13] African Union (AU). 2015. The African Union Commission Agenda 2063: The Africa We Want First Ten-Year Implementation Plan 20132023. Available: www.au.int/en/agenda2063/aspirations.

[14] K. C. Mofolorunsho, "Outbreak of Lassa fever in Nigeria: measures for prevention and control," The Pan African Medical Journal, 2016, 23: 210.

[15] Nigeria Centre for Disease Control. (2017). "Lassa fever Outbreak, Weekly Situation Report No. 04. 1-3". Retrieved from http://www.health.gov.ng/doc/lassa17.pdf.

[16] A. Maxmen. "Deadly outbreak tests Nigerian health agency Reforms made after the Ebola epidemic have boosted Nigeria's capacity to track diseases" Nature, 2018, 555: 421-422.

[17] R. C. Reuben, S. D. Gyar, M. D. Makut, and M. P. Adoga, "Coepidemics: have measures against COVID-19 helped to reduce Lassa fever cases in Nigeria?" New Microbe and New Infect., 2021; 40(C): 17.

[18] J. O. Adesoji, M. A. Yinusa, J. A. Adijat, R., Abdulateef, K. Kehinde, I. Akindele, "Knowledge beliefs and sources of information on Lassa fever among residents of a community in Ilorin Nigeria." Romanian Journal of Sociological Studies, 2016, New Series, 2, 153-166.

[19] E. U. Nwonwu, C. Alo, A. F. Una, U. C. Madubueze, I. Eze, N. C, Eze, L. U. Ogbonnaya, and I. C. Akamike, "Knowledge of Lassa fever and Its Determinants among Traders in Izzi Community in South-East Nigeria". Archives of Current Research International, 2018, 13(4): 19.

[20] F. Ireye, H. Ejiyere,, A. O. Aigbiremolen O. E. Famiyesin, E. A. Rowland-Udoh, C. O. Ogeyemhe, I. Okudo, A. B. Onimisi, "Knowledge, Attitude and Infection Prevention and Control Practices Regarding Lassa fever among Healthcare Workers in Edo State, Nigeria." International Journal of Prevention and Treatment 2019, 8(1): 21-27.

[21] I. S. Akpan, and A. E. Ekuma, "Lassa fever and Infection Control: Knowledge, Attitudes and Practice in A University Teaching Hospital in Uyo, Nigeria." Ibom Medical Journal 2017. 10(1): 40-47.

[22] R. C. Reuben, and S. D. Gyar, "Knowledge, attitudes and practices of Lassa fever in and around Lafia, Central Nigeria." International Journal of Public Health and Epidemiology Research, 2016, 2(1): 014019.

[23] E. O. Ogboghodo, V. Y. Adam, V. O. Omuemu, O. H. Okojie, "Knowledge, Attitude and Preventive Practices against Lassa fever Among Residents in a Rural Community in Southern Nigeria" West African Journal of Medicine, 2019, 36(2):165-171.

[24] S. A. Olowookere, C. A., Adegbenro, A., Idowu, A. G., Omisore O. M. Shabi, U. R., Ikem, G. A. Ekwere, and I. F. Oderinde, "Knowledge Attitude and Practices toward Lassa fever Control and Prevention among Residents of Ile-Ife, Southwest Nigeria." International Quarterly of Community Health Education, 2017. 37(2) 107-112. 